\title{
Mosaic Patterns of B-vitamin Synthesis and Utilization in a Natural Marine Microbial Community
}

\author{
Laura Gómez-Consarnau 1*, Rohan Sachdeva', Scott M. Gifford², Lynda S. Cutter', Jed A. Fuhrman', \\ Sergio A. Sañudo-Wilhelmy ${ }^{1,3}$, Mary Ann Moran ${ }^{4}$
}

Aquatic environments contain diverse microbial communities whose complex interactions mediate the cycling of major and trace nutrients such as vitamins. B-vitamins are essential coenzymes that many organisms cannot synthesize. Thus their exchange among de-novo synthesizers and auxotrophs is expected to play an important role in the microbial consortia and explain some of the temporal and spatial changes observed in diversity. In this study, we analyzed metatranscriptomes of a natural coastal microbial community, diel sampled- quarterly over one year to try to identify the potential major B-vitamin synthesizers and consumers. Our transcriptomic data show that the best-represented taxa dominated the expression of synthesis genes for some B-vitamins but lacked transcripts for others. For instance, Rhodobacterales dominated the expression of vitamin- $\mathrm{B}_{12}$ synthesis, but not of vitamin- $\mathrm{B}_{7}$, whose synthesis transcripts were mainly represented by Flavobacteria. In contrast, bacterial groups that constituted less than $4 \%$ of the community (e.g., Verrucomicrobia) accounted for most of the vitamin- $\mathrm{B}_{1}$ synthesis transcripts. Furthermore, ambient vitamin- $\mathrm{B}_{1}$ concentrations were higher in samples collected during the day, and were positively correlated with chlorophyll- $a$ concentration. Our analysis supports the hypothesis that the mosaic of metabolic interdependencies through B-vitamin synthesis and exchange are key processes that contribute to shaping microbial communities in nature.

\section{Introduction}

Aquatic environments contain large communities of microorganisms whose complex synergistic chemical interactions mediate the transfer of energy and the cycling of major and trace nutrients. Molecular studies have shown that marine microbial systems are extremely diverse, containing thousands of different taxa that combined presumably sustain ecosystem functioning (Sogin et al., 2006). In general, while a few species numerically dominate a particular microbial community, they are complemented by a large number of less abundant species whose specific function is not well understood (Pedrós-Alió, 2012). For example, similar to the Hutchinson's paradox of the plankton (Hutchinson, 1961), it is unclear why the marine heterotrophic bacterioplankton community is so diverse at certain locations if all share the same niche and ecological functions (Moran, 2008). Ultimately, recognizing the connectivity among the species that compose the heterotrophic bacterioplankton community represents a key to understanding the fate of up to half of the marine primary production that is routed through the microbial loop (Azam et al., 1983). Field and laboratory studies have shown that resource allocation from algal-derived organic matter could explain some marine bacterioplankton successions and the dominance of certain microbial taxa capable of distinct decomposition pathways (McCarren et al., 2010; Teeling et al., 2012). However, these mechanisms cannot explain the

'Department of Biological Sciences, University of Southern California, 90089 Los Angeles, CA, USA. ${ }^{2}$ Department of Marine Sciences, University of North Carolina at Chapel Hill, Chapel Hill, NC, 27599 USA. ${ }^{3}$ Department of Earth Science, University of Southern California, 90089 Los Angeles, CA, USA. ${ }^{4}$ Department of Marine Sciences, University of Georgia, Athens, GA, 30602 USA.

*E-mail:gomezcon@usc.edu large background heterotrophic community that exists under non-bloom conditions during most of the year. In contrast, the bacterial connectivity and diversity observed in microbial communities could reflect complex interdependencies associated with external metabolites such as the B-vitamins, as observed in mixed culture experiments (Croft et al., 2005).

B-vitamins are the most versatile and ancient coenzymes (Monteverde et al., 2017). They catalyze a wide spectrum of critical metabolic reactions, such as the tricarboxylic acid (TCA) and Calvin cycles (thiamin; vitamin- $\mathrm{B}_{1} ; \mathrm{VB}_{1}$ ), carbon fixation via the reverse TCA cycle (biotin; vitamin- $\mathrm{B}_{7} ; \mathrm{VB}_{7}$ ) or the synthesis of methionine (cobalamin; vitamin- $\mathrm{B}_{12}, \mathrm{VB}_{12}$ ) (Sañudo-Wilhelmy et al., 2014). Vitamin $\mathrm{B}_{6}$ (pyridoxine, $\mathrm{VB}_{6}$ ) seems to be remarkably important as it catalyzes almost $2 \%$ of all prokaryotic functions (Percudani and Peracchi 2003) and yet, has rarely been studied in marine systems (SañudoWilhelmy et al., 2012). Despite their relevance, B-vitamins auxotrophy is widespread among marine eukaryotes (Croft et al., 2006, Tang et al., 2010; Paerl et al., 2015) and may influence the taxonomic composition of phytoplankton communities as well as the rates of primary production and carbon fixation (Panzeca et al., 2006; Sañudo-Wilhelmy et al., 2006; Koch et al., 2011). For decades, it was assumed that marine prokaryotes were the source of exogenous B-vitamins for marine phytoplankton (Kurata 1986; Croft et al., 2005). However, the extensive genomic information that is now available suggests that not all bacteria and archaea are de-novo synthesizers (LeBlanc et al. 2011; Sañudo-Wilhelmy et al., 2014). For example, the highly streamlined Candidatus Pelagibacter ubique lacks the biosynthetic pathways for $\mathrm{VB}_{1}, \mathrm{VB}_{5}$, and $\mathrm{VB}_{7}$, and can reach concentrations of $10^{9}$ cells $\mathrm{ml}^{-1}$ only when these vitamins are present, regardless of how much $\mathrm{C}, \mathrm{N}$ or $\mathrm{P}$ is available (Carini et al., 2012). This 
bioRxiv preprint doi: https://doi.org/10.1101/280438; this version posted March 14,2018 . The copyright holder for this preprint (which was not certified by peer review) is the author/funder, who has granted bioRxiv a license to display the preprint in perpetuity. It is made available under aCC-BY-NC-ND 4.0 International license.

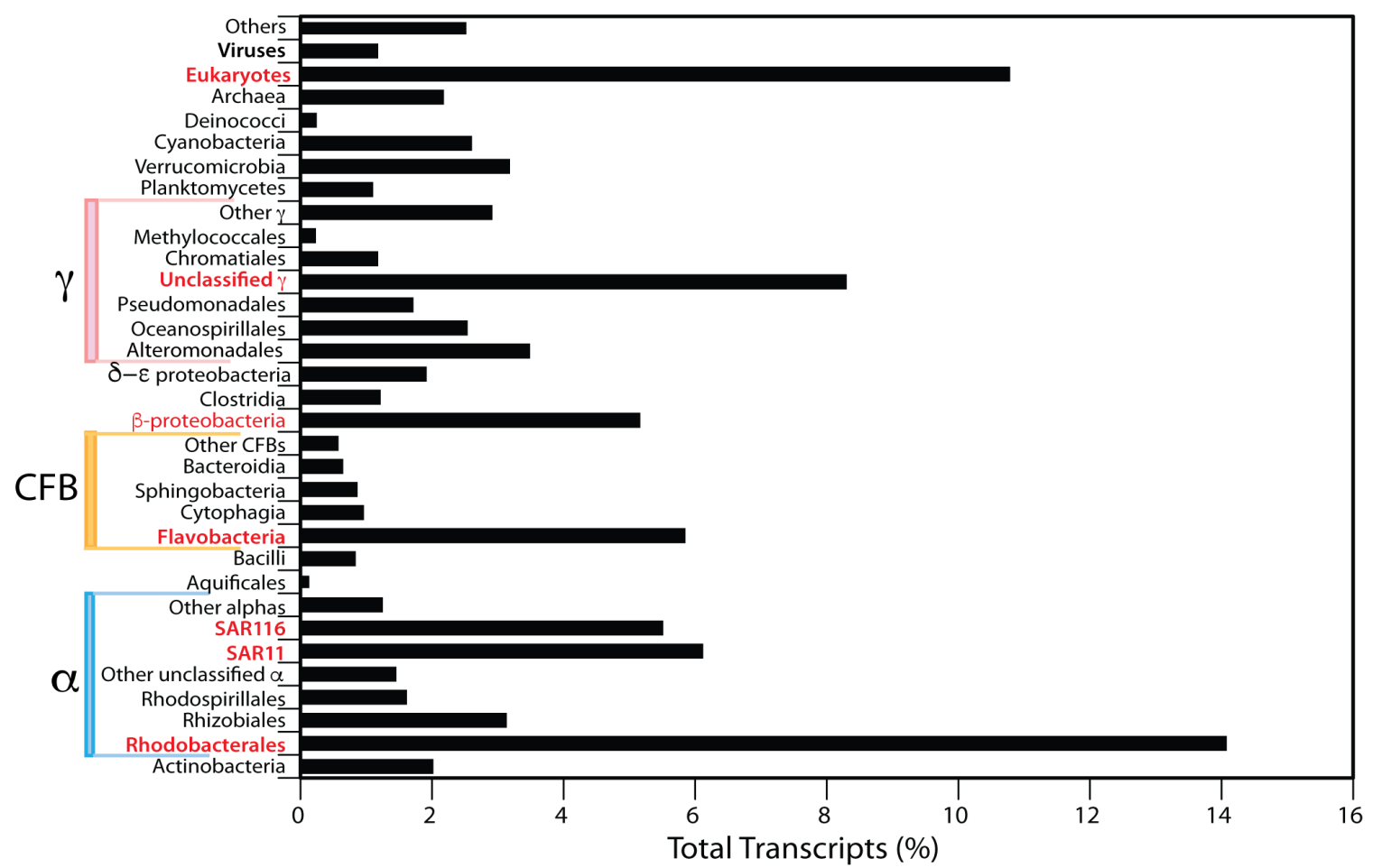

Figure 1. Percentage of the total transcripts detected in 16 southeastern U.S. metatranscriptomes, classified by taxon. Red font indicates the best-represented taxonomic groups as determined from mRNA abundance. The symbols $\alpha, \beta, \gamma, \delta$ and $\varepsilon$ refer to the different proteobacteria classes. CFB refer to the Cytophaga-Flavobacterium-Bacteroides (CFB) phylum.

example alone suggests that exogenous sources of B-vitamins (dissolved and/or particulate) must be available within the water column. The hypothetical direct or indirect "metabolic cooperation" (Raes and Bork, 2008) among the bacterio- and phytoplankton particle-associated communities via vitamin exchange has been intuited from results of experiments using isolated strains in culture (Croft et al., 2005; Wagner-Döbler et al., 2010; Kazamia et al., 2012). Furthermore, dissolved vitamins are also released into the environment through processes that do not involve direct microbial interactions, as $\mathrm{VB}_{12}$ excretion during cell division has been observed in pure cultures of cyanobacteria (Bonnet et al., 2010). Regardless of whether or not B-vitamin auxotrophs rely on direct or indirect microbial exchange to obtain these metabolites, the identification of the potential vitamin producers and consumers in a natural microbial community is important for understanding the processes sustaining the ecosystem. Recent work of Heal et al. (2017) studied the potential $\mathrm{VB}_{12}$ interdependencies among producers and consumers in the North Pacific Ocean. However, the study of these ectocrine interactions remains largely unfinished, as they have not been examined for other B-vitamins and in other marine environments.

In this study, we used metatranscriptomics to identify the transcriptional investment of different taxa in B-vitamin synthesis and utilization for $\mathrm{VB}_{1}, \mathrm{VB}_{6}, \mathrm{VB}_{7}$ and $\mathrm{VB}_{12}$ within a natural coastal marine microbial community. Our data show that some of the best-represented taxa dominated the expression of synthesis genes for some, but not all B-vitamins, suggesting the need for metabolite exchange among microbial groups. The concentration of dissolved $\mathrm{VB}_{1}$ and $\mathrm{VB}_{6}$ in this environment followed diel oscillations, with higher levels during the day compared to night. These environmental diel fluctuations of B-vitamins could be related to their metabolic function as protectants against oxidative stress and potentially constitute a mechanism of vitamin supply to the auxotrophic members of the community.

\section{Results and Discussion}

\section{Microbial community composition}

Taxonomic diversity of metabolically active bacteria through the different seasons was estimated using the total number of transcripts recruited for each microbial group (Gifford et al., 2014). Total community expression was represented by bacterial taxa that are typically found in marine coastal ecosystems (Gifford et al., 2013; 2014), including Alphaproteobacteria (Rhodobacterales, relative expression 11-18\%; SAR 11, 1-14\%; SAR 116, 3-7\%), Flavobacteria (2-11\%), Gammaproteobacteria (unclassified, 6-11\%) and Betaproteobacteria (3-7\%) (Figure 1 and Table S3). Eukaryotic mRNAs were the second-most expressed transcripts detected after Rhodobacterales in this 3.0-micron pre-filtered community (on average $\sim 11 \%$ of reads; range $4-38 \%$ ), and were particularly important during periods of high chlorophyll-a (Chl- $a$ ) (Summer '08, Fall '08 and Spring '09, accounting for $18-38 \%$ of the total mRNA library). The microbial picoeukaryotic taxa with the highest expression in this 0.2 to $3.0 \mu \mathrm{m}$ plankton size fraction were Micromonas (20-44\% of eukaryotic sequences), Ostreococcus (20- 
bioRxiv preprint doi: https://doi.org/10.1101/280438; this version posted March 14,2018 . The copyright holder for this preprint (which was not certified by peer review) is the author/funder, who has granted bioRxiv a license to display the preprint in perpetuity. It is made available under aCC-BY-NC-ND 4.0 International license.

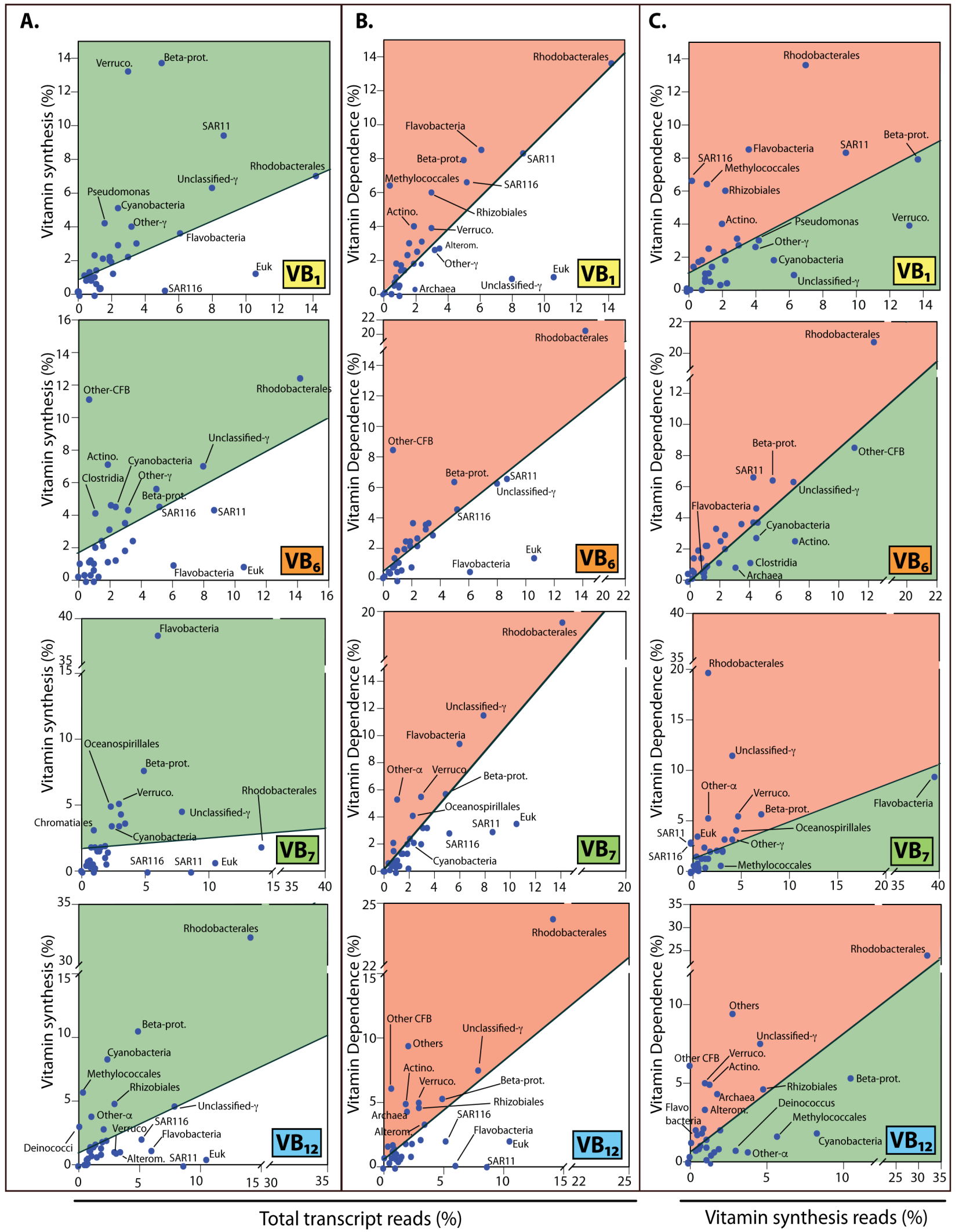

Figure 2. B-vitamin synthesis and dependence transcripts in different microbial taxa. A) Percentage of B-vitamin synthesis transcripts and B) percentage of vitamin dependent transcripts compared to the total transcript abundance for each taxonomic group. C) Percentage of B-vitamin synthesis transcripts vs. percentage of B-vitamin dependence transcripts. Green areas show the microbial groups with a higher percentage of the community vitamin synthesis transcripts compared to total transcript abundance (A) or the percentage of their vitamin dependent gene transcripts $(\mathrm{C})$. Red areas show the microbial groups with a higher percentage of vitamin-dependent transcripts as compared to total transcript abundance $(\mathrm{B})$ or B-vitamin synthesis transcripts $(\mathrm{C})$. It is assumed that the microbial groups on the regression line have a neutral impact in the community, as vitamin synthesis processes are relatively well balanced with their requirements. Regression lines are determined by outlier removal with IWLS (10 6 maximum iterations, Table S4). 
Table 1. Total number of B-vitamin synthesis and dependence transcripts found in our study. Values in parentheses are the percentages of the B-vitamin reads in the dataset.

\begin{tabular}{ccc} 
& \multicolumn{2}{c}{ N. Transcripts } \\
\cline { 2 - 3 } Vitamin & Synthesis & Dependent \\
\hline $\mathbf{V B}_{\mathbf{1}}$ & $4,921(0.04 \%)$ & $101,501(0.78 \%)$ \\
$\mathbf{V B}_{\mathbf{6}}$ & $6,856(0.05 \%)$ & $89,474(0.69 \%)$ \\
$\mathbf{V B}_{\mathbf{7}}$ & $2,540(0.02 \%)$ & $36,364(0.28 \%)$ \\
$\mathbf{V B}_{\mathbf{1 2}}$ & $5,546(0.04 \%)$ & $17,592(0.14 \%)$ \\
\hline
\end{tabular}

39\%) and Chlorella-like (5-36\%; Table 2, Table S3). The relative increase in expression of certain bacterioplankton groups during the Chl-a peaks (e.g. Flavobacteria during the phytoplankton bloom of Winter '09) is consistent with similar trends repeatedly reported in the literature (Kirchman, 2002; Teeling et al., 2012). However, the relative contribution of the major microbial community taxa to total community transcripts remained relatively stable during our year-long study (e.g. SAR11, SAR116, Rhodobacterales, Betaproteobacteria; Figure 1, Table S3). Archaeal transcripts reached $7.5-10.5 \%$ of all transcripts during summer 08 and were also high but to a lesser extent in summer ' 09 (2-4\% of all transcripts), while they were low in all other seasons (Hollibaugh et al., 2011; 2013). Other taxonomic groups such as Cyanobacteria and Verrucomicrobia were also present throughout the year although comprising less than $4 \%$ of the prokaryotic expression (Figure 1, Table S3).

\section{Expression of vitamin synthesis and vitamin-dependent metabolisms}

The correlation between gene expression and the actual associated metabolic process in the environment is not always easy to discern (Gifford et al., 2011). It is currently known that the ratio between mRNA and protein can be quite variable and may not quantitatively reflect the immediate cell response to environmental changes (Taniguchi et al., 2010). The inability to predict protein levels from mRNA could be explained by the long half-life of proteins compared to mRNA, in addition to variable post-transcriptional modifications and translation efficiencies among other factors (Moran et al., 2013). Nevertheless, metatranscriptomics is a powerful tool to identify patterns that can be used to identify the potential organisms involved in different environmental processes. To try to understand B-vitamin synthesis and utilization in this coastal environment, we quantified the total number of annotatable transcripts involved in the synthesis of $\mathrm{VB}_{1}, \mathrm{VB}_{6}, \mathrm{VB}_{7}$ and $\mathrm{VB}_{12}$, as well as their vitamin-dependent enzymes (Table 1, Table S1). This semiquantitative approach allows the evaluation of the overall transcript investment in B-vitamin synthesis and dependent functions within metatranscriptomes. On the synthesis side, the highest number of transcripts was found for $\mathrm{VB}_{6}$ synthesis $\left(0.05 \%\right.$ of the community transcriptome), followed by $\mathrm{VB}_{12}$,
$\mathrm{VB}_{1}$, and $\mathrm{VB}_{7}$ (Table 1). On the dependence side, the majority of vitamin-dependent functions detected in the microbial community were ascribed to $\mathrm{VB}_{1}$, with 101,501 reads $(0.78 \%$ of total reads) (Table 1), consistent with the importance of $\mathrm{VB}_{1}$-dependent enzymes in central metabolism (Table S1). $\mathrm{VB}_{6}$ had the second highest number of vitamin-dependence transcripts $\left(0.69 \%\right.$ of all reads), followed by $\mathrm{VB}_{7}$ and $\mathrm{VB}_{12}$. Differences in the number of synthesis or dependence transcripts between the vitamins is likely to reflect variations in the complexity of their biosynthesis pathways, the number of reactions that require them, the times they can be reused, and the efficiency of their cellular salvage pathways.

\section{Identification of B-vitamin synthesizers within the microbial community}

We further analyzed the taxonomic distribution of vitamin synthesis and utilization transcripts among the members of the microbial community (Figure 2, Tables S3 and S2). Figure 2 shows the percent of community transcripts for vitamin synthesis or dependence that is attributed to a taxon. Some of the best-represented taxa dominated the expression of several vitamin synthesis pathways. Rhodobacterales, the most transcriptionally abundant bacterial group identified in this study, was potentially the major producer of $\mathrm{VB}_{12}$, accounting for almost $50 \%$ of all the environmental $\mathrm{VB}_{12}$ synthesis transcripts in some samples $\left(\mathrm{VB}_{12}\right.$ synthesis:total transcript ratio had a residual of $27 \%$ from the communitywide vitamin regression line; Figure 2A, Table S4). This is in contrast to what was reported from incubation experiments in the Southern Ocean, in which Oceanospirillaceae appeared to be the major $\mathrm{VB}_{12}$ synthesizers (Bertrand et al., 2015). However, because Rhodobacterales $\mathrm{VB}_{12}$ dependence transcript abundance was also high, their $\mathrm{VB}_{12}^{12}$ dependence:synthesis transcript ratio was typical for this community $\left(\mathrm{VB}_{12}\right.$ dependence:synthesis ratio had a residual of less than $2 \%$ from the community-wide regression line; Figure 2C). For other B-vitamins, though, Rhodobacterales vitamin-synthesis transcripts were clearly below the typical dependence:synthesis transcript relationship. For $\mathrm{VB}_{1}$ and $\mathrm{VB}_{6}$, only $7 \%$ and $12 \%$ of the synthesis transcripts belonged to Rhodobacterales, while they were responsible for a 2-fold higher percentage of the vitamin-dependent gene transcripts (dependence:synthesis residuals of $9 \%$ and $10 \%$, respectively; Figure 2, Table S4). Their dependence:synthesis transcript relationship for $\mathrm{VB}_{7}$ was even more unbalanced with $2 \%$ of the community synthesis genes compared to $20 \%$ of the community requirement (synthesis-dependence residuals of 18\%; Figure 2C, Table S3, S4). These field-based results are consistent with genomes from isolated marine strains showing that while almost all of the cultured Rhodobacterales can synthesize vitamin- $\mathrm{B}_{12}$, only $50 \%$ and $70 \%$ can produce $\mathrm{VB}_{1}$ and $\mathrm{VB}_{7}$ respectively (Sañudo-Wilhelmy et al., 2014). Figure 3 further shows the percentage of mRNA sequences that each phylogenetic group invested in B-vitamin synthesis and dependent processes. This analysis allows to qualitatively distinguish to what extent the different taxa rely on B-vitamin metabolism compared to the average community. Similarly to the total transcript analysis (Figure 2), Rhodobacterales 
bioRxiv preprint doi: https://doi.org/10.1101/280438; this version posted March 14,2018 . The copyright holder for this preprint (which was not certified by peer review) is the author/funder, who has granted bioRxiv a license to display the preprint in perpetuity. It is made available under aCC-BY-NC-ND 4.0 International license.

invested a remarkably small percentage of their transcripts in $\mathrm{VB}_{7}$ synthesis, and to a lesser extent, in the production of $\mathrm{VB}_{6}$, and $\mathrm{VB}_{1}$. In contrast, the percentage of transcripts invested in $\mathrm{VB}_{12}$ synthesis and dependent processes by Rhodobacterales was close to the community average (Figure 3). This suggests that in order to maintain their high level of total expression in this microbial ecosystem (Figure 1), the Rhodobacterales may rely on other external vitamin sources (e.g. $\mathrm{VB}_{7}$ produced by other microbes).

Flavobacteria were also well represented and dominated the expression of $\mathrm{VB}_{7}$ synthesis genes, contributing as much as $64 \%$ of the total community synthesis transcripts for this vitamin $(38 \%$ on average; Figure $2 \mathrm{~A}$, Table S3 and S4). Moreover, the $\mathrm{VB}_{7}$ requirements for this group were also higher than typical (Figure 2), suggesting a potentially high $\mathrm{VB}_{7}$ synthesis, usage and, thus, turnover for this group. It is currently known that different members of Flavobacteria, even close species of the same genus, have different vitamin- $B_{1}$ synthesis capabilities (Gómez-Consarnau et al., 2016). However, as a group compared to the community average, Flavobacteria expressed a higher percentage of $\mathrm{VB}_{1}$ dependence transcripts compared to synthesis $(4 \%$ compared to $9 \%$ on average, respectively; Figure $2 \mathrm{BC}$, Table S3 and $\mathrm{S} 4)$. $\mathrm{VB}_{12}$ synthesis gene transcripts were low in Flavobacteria (1\% of the community). Furthermore, the expression of genes for $\mathrm{VB}_{12}$ dependent functions was almost absent $(0.1 \%$ on average), suggesting a low requirement for this vitamin. This is consistent with the observation that none of the whole genome sequenced Flavobacteria available have a complete pathway for $\mathrm{VB}_{12}$ synthesis (Sañudo-Wilhelmy et al., 2014). Notably, the percentage of $\mathrm{VB}_{7}$ transcript synthesis was higher in this group than in any other taxon $(0.12 \%$ of all Flavobacteria transcripts; Figure 3). The potentially significant $\mathrm{VB}_{7}$ contribution from Flavobacteria to the bacterial community and its $\mathrm{VB}_{1}$ dependence are also consistent with whole genome results showing that about $60 \%$ of the sequenced cultures of that group produce $\mathrm{VB}_{7}$ but only $25 \%$ can synthesize $\mathrm{VB}_{1}$ and none can make $\mathrm{VB}_{12}$ (Sañudo-Wilhelmy et al., 2014). However, our analysis showed that neither of the two Flavobacteria reference genomes that recruited the most transcripts in our study, Flavobacteria strains MS024-2A and MS024-3C, have the complete pathway to synthesize $\mathrm{VB}_{7}$ de-novo (Table S3). These organisms only partially expressed the $\mathrm{VB}_{7}$ synthesis pathway and would potentially require the combined

Table 2. Presence of B-vitamin synthesis genes and pathways for the 30 most abundant genomes (according to total transcripts) found in the Sapelo island metatranscriptome. Vitamin-B synthesis was determined using the thiC-thi5 and thiG-thi4 genes for the production of the 4-amino-5-hydroxymethylpyrimidine (HMP) and 4-methyl-( $\beta$-hydroxyethyl) thiazole (THZ) moieties, respectively; Vitamin- $\mathrm{B}_{6}$ synthesis was determined by the presence of the $\mathrm{pdxJ}$ gene. Vitamin- $\mathrm{B}_{7}$ synthesis was determined using the bioB biotin synthase gene. To account for possible misannotations of single genes on the vitamin- $\mathrm{B}_{12}$ synthesis pathway, it was considered present when a genome contained more than $75 \%$ of the $\mathrm{VB}_{12}$ de-novo synthesis clusters of orthologous groups (COGs) retrieved from the Integrated Microbial Genomes database (http://img.jpi.doe.gov) (COG0007, COG0310, COG0368, COG1010, COG1270, COG1429, COG1492, COG1797, COG1903, COG2073, COG2082, COG2087, COG2099, COG2109, COG2241, COG2242, and COG2243), as previously reported by Sañudo-Wilhelmy et al. (2014).

\begin{tabular}{|c|c|c|c|c|c|c|c|c|c|}
\hline & & & & Total hits & $\begin{array}{l}\text { VB1-HMP } \\
\text { (ThiC/thi5) }\end{array}$ & $\begin{array}{l}\text { VB1-HET-P } \\
\text { (thiG/thi4) }\end{array}$ & $\begin{array}{l}\text { VB6 } \\
(p d x J)\end{array}$ & $\begin{array}{l}\mathrm{VB} 7 \\
(\text { bioB })\end{array}$ & $\begin{array}{l}\mathrm{VB} 12 \\
*\end{array}$ \\
\hline \multirow{26}{*}{ Bacteria } & \multirow{12}{*}{ Alphaproteobacteria } & \multirow{6}{*}{$\begin{array}{c}\text { unclassified } \\
\text { Alphaproteobacteria }\end{array}$} & Candidatus Puniceispirillum marinum IMCC1322 & 610,543 & $x$ & $\checkmark$ & $\checkmark$ & $\times$ & $\boldsymbol{V}$ \\
\hline & & & Candidatus Pelagibacter sp. HTCC7211 & 543,968 & $x$ & $\checkmark$ & $\boldsymbol{V}$ & $x$ & $\times$ \\
\hline & & & Candidatus Pelagibacter ubique HTCC 1002 & 188,171 & $x$ & $\checkmark$ & $\checkmark$ & $\times$ & $x$ \\
\hline & & & Candidatus Pelagibacter ubique HTCC1062 & 122,266 & $x$ & $\checkmark$ & $\boldsymbol{V}$ & $x$ & $\times$ \\
\hline & & & Candidatus Pelagibacter sp. IMCC9063 & 68,417 & $x$ & $\checkmark$ & $\checkmark$ & $x$ & $x$ \\
\hline & & & alpha proteobacterium BAL199 & 132,928 & $\boldsymbol{v}$ & $\checkmark$ & $\checkmark$ & $x$ & 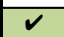 \\
\hline & & \multirow{6}{*}{ Rhodobacterales } & Roseobacter sp. AzwK-3b & 69,182 & $x$ & 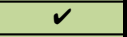 & $\boldsymbol{V}$ & $x$ & $\checkmark$ \\
\hline & & & Silicibacter lacuscaerulensis ITI-1157 & 60,964 & $x$ & $\checkmark$ & $\boldsymbol{V}$ & $x$ & $\checkmark$ \\
\hline & & & Dinoroseobacter shibae DFL 12 & 51,176 & $\boldsymbol{V}$ & $\checkmark$ & $\boldsymbol{V}$ & $x$ & 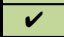 \\
\hline & & & Rhodobacteraceae bacterium HTCC2083 & 76,242 & $x$ & $x$ & $\boldsymbol{V}$ & $x$ & $\checkmark$ \\
\hline & & & Rhodobacterales bacterium HTCC 2255 & 61,449 & $x$ & $x$ & $\boldsymbol{V}$ & $x$ & $\checkmark$ \\
\hline & & & Rhodobacteraceae bacterium HTCC 2150 & 53,528 & $x$ & $x$ & 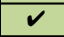 & $x$ & $\checkmark$ \\
\hline & \multirow{7}{*}{ Gammaproteobacteria } & \multirow{7}{*}{\begin{tabular}{|c|} 
\\
unclassified \\
Gammaproteobacteria
\end{tabular}} & marine gamma proteobacterium HTCC2080 & 188,652 & $x$ & $x$ & $v$ & $x$ & $x$ \\
\hline & & & gamma proteobacterium HTCC2207 & 126,002 & $x$ & $x$ & $\checkmark$ & $\boldsymbol{V}$ & $\times$ \\
\hline & & & gamma proteobacterium IMCC3088 & 108,019 & $\times$ & $x$ & $\checkmark$ & $x$ & $x$ \\
\hline & & & marine gamma proteobacterium HTCC 2143 & 92,583 & $x$ & $x$ & $\boldsymbol{V}$ & $x$ & $\times$ \\
\hline & & & marine gamma proteobacterium HTCC2148 & 80,092 & $x$ & $x$ & $\checkmark$ & $\boldsymbol{V}$ & $x$ \\
\hline & & & gamma proteobacterium NOR51-B & 116,949 & $x$ & $\times$ & $\checkmark$ & $x$ & $\times$ \\
\hline & & & gamma proteobacterium NOR5-3 & 61,805 & $\times$ & $x$ & $\checkmark$ & $\times$ & $\times$ \\
\hline & \multirow[b]{2}{*}{ Betaproteobacteria } & Methylophilales & Methylophilales bacterium HTCC2181 & 66,512 & $\boldsymbol{V}$ & $\checkmark$ & $\boldsymbol{V}$ & $\boldsymbol{v}$ & $x$ \\
\hline & & $\begin{array}{c}\text { unclassified } \\
\text { Betaproteobacteria } \\
\end{array}$ & beta proteobacterium KB 13 & 71,029 & $\checkmark$ & $\checkmark$ & $\boldsymbol{v}$ & $\boldsymbol{v}$ & $x$ \\
\hline & \multirow{2}{*}{ Bacteroidetes } & \multirow{2}{*}{ Flavobacteriia } & Flavobacteria bacterium MS024-2A & 126,000 & $x$ & $x$ & $\checkmark$ & $x$ & $\times$ \\
\hline & & & Flavobacteria bacterium MS024-3C & 65,893 & $x$ & $x$ & $\checkmark$ & $x$ & $x$ \\
\hline & \multirow{3}{*}{ Verrucomicrobia } & Opitutae & Coraliomargarita akajimensis DSM 45221 & 97,641 & $v$ & $\checkmark$ & $\boldsymbol{V}$ & $v$ & $x$ \\
\hline & & \multirow{2}{*}{ Verrucomicrobiae } & Pedosphaera parvula Ellin514 & 75,244 & $\checkmark$ & $\checkmark$ & $\checkmark$ & $\boldsymbol{V}$ & $\times$ \\
\hline & & & Verrucomicrobiae bacterium DG1235 & 62,508 & $x$ & $x$ & $\boldsymbol{v}$ & $\times$ & $x$ \\
\hline Archaea & Nitrosopumilales & Nitrosopumilaceae & Nitrosopumilus maritimus SCM1 & 164,627 & $\checkmark$ & 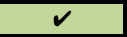 & $\checkmark$ & $V$ & $\checkmark$ \\
\hline \multirow{3}{*}{ Eukaryota } & \multirow{3}{*}{\multicolumn{2}{|c|}{ Chlorophyta }} & Micromonas sp. RCC299 & 139,279 & $x$ & $x$ & $v$ & $v$ & $\times$ \\
\hline & & & Ostreococcus tauri & 103,422 & $x$ & $x$ & $\boldsymbol{V}$ & $\boldsymbol{V}$ & $\times$ \\
\hline & & & Chlorella variabilis & 63,212 & $v$ & $\checkmark$ & $v$ & $v$ & $x$ \\
\hline
\end{tabular}


enzymatic activity of other bacteria to be able to obtain $\mathrm{VB}_{7}$. Alternatively, it is possible that recruitment to Flavobacteria reference genomes split transcripts from a single population into different genome bins. Nevertheless, our data suggests that Flavobacteria, whether they have the complete gene set for $\mathrm{VB}_{7}$ or not, potentially occupy an important niche for its production in this community.

Members of the SAR 11 and SAR 116 clades were also well represented in our samples $(9 \%$ and $5 \%$ on average; Figure 1 , Table S3), and they are both auxotrophic for $\mathrm{VB}_{1}$ and $\mathrm{VB}_{7}$. However, Candidatus Puniceispirillum marinum IMCG1322, the SAR 116 genome recruiting the greatest number of reads in our samples, can synthesize $\mathrm{VB}_{12}$, while members of the SAR 11 clade neither synthesize nor have requirements for this vitamin (Giovannoni et al., 2005; Figure 2, Table S3). The percentage of community transcripts for both $\mathrm{VB}_{12}$ synthesis and dependence for SAR116 was the same (2 $\%$ ), suggesting that their $\mathrm{VB}_{12}$ synthesis could meet their requirements (Table S3). SAR11 and SAR116 genomes have incomplete pathways for the synthesis of $\mathrm{VB}_{1}$ and can only produce one of the two moieties that form the thiamin molecule (4-methyl-5-(2-phosphoethyl)-thiazole, THZ) (Carini et al., 2014). SAR11 VB 1 synthesis genes accounted for $10 \%$ of all the community transcripts while the $\mathrm{VB}_{1}$ dependent functions were about $8 \%$ (Figure 2). However, they would need to acquire the other $\mathrm{VB}_{1}$ moiety (4-amino5-hydroxymethyl-2-methylpyrimidine, HMP) from the environment. In contrast to SAR11, SAR116 VB synthesis transcripts were nearly absent $(0.3 \%)$ while their $\mathrm{VB}_{1}$ requiring transcripts made up to $7 \%$ of the community $\left(\mathrm{VB}_{1}\right.$ dependence:synthesis residuals of $6 \%$; Figure 2C, Table S3), suggesting a strong dependence on exogenous sources of $\mathrm{VB}_{1}$. In line with the total community transcriptomic data analysis (Figure 2), the percentage of SAR 11 and SAR 116 transcripts invested in B-vitamin metabolism was low, only being slightly above the average community value for $\mathrm{VB}_{1}$ synthesis in SAR1 1 and dependence in SAR 116 (Figure 3).

Although the small eukaryotes $(<3 \mu \mathrm{m})$ accounted for up to $38 \%$ of the total transcripts (Figure 1, Table S3), their B-vitamin synthesis genes always remained under $6 \%$ of the community B-vitamin synthesis transcripts (Figure 2A, Table S3). Furthermore, the eukaryotic B-vitamin dependent gene transcripts remained under $11 \%$, suggesting that their B-vitamin requirements were also relatively low (Figure 2B, Table S3). This observation was consistent with the percent of eukaryotic transcripts invested in B-vitamin metabolism, which remained below the community average for all the vitamins (Figure 3). This was unexpected since eukaryotic phytoplankton have been considered major vitamin-dependent organisms of the microbial plankton (Croft et al., 2005; Tang et al., 2010). However, complex regulatory processes in response to iron limitation (Cohen et al., 2017) or riboswitch controls (McRose et al., 2014) may impact the expression of vitamin-related genes, as observed in eukaryotic alga. Another important consideration is that some eukaryotic phytoplankton could synthesize some vitamins using a non-canonical pathway. For instance, Emiliania Huxleyi can grow using either a complete $\mathrm{VB}_{1}$ molecule or only one of the $\mathrm{VB}_{1}$-forming moieties (HMP) while lacking the genes that encode for the other moiety (HET-P; 4-methyl-5-b-hydroxyethylthiazole adenosine diphosphate), suggesting an alternative uncharacterized VB synthesis pathway (McRose et al., 2014). In contrast, picoeukaryotic algae (e.g. Micromonas and Ostreococcus) can utilize $\mathrm{VB}$ but not the individual moieties that form the vitamin (McRose et al., 2014, Paerl et al., 2015). Instead these picoeukaryotic phytoplankton are able to meet their $\mathrm{VB}_{1}$ requirements using a still chemically uncharacterized HET-P precursor together with HMP (Paerl et al., 2017). Finally, larger eukaryotic phytoplankton groups $(>3 \mu \mathrm{m})$ were not included in this analysis and may have a more skewed ratio of synthesis to dependence transcripts.

In contrast to eukaryotic phytoplankton, betaproteobacterial $\mathrm{B}$-vitamin synthesis genes were high for $\mathrm{VB}_{1}$ and $\mathrm{VB}_{12}$ (average: $14 \%$ and $10 \%$ respectively) and for $\mathrm{VB}_{7}(8 \%)$ (Figure 2; Table S3) and their vitamin dependence genes generally accounted for a similar percent of the community (close to the typical regression lines, Figure 2), suggesting that this bacterial group was very active and self-sufficient at producing and utilizing these B-vitamins. Consistent with this observation, the percentage of total betaproteobacterial transcripts invested in B-vitamin metabolism appeared to always be above the community average (Figure 3). However, there were significant differences in the number of $\mathrm{VB}_{12}$ synthesis and dependence transcripts within Betaproteobacteria (Table S2). While the abundant betaproteobacterial genomes dominated the $\mathrm{VB}_{12}$ requirement transcripts (e.g. Methylovorus glucosetrophus SIP3-4, beta proteobacterium KB13, or Methylophilales bacterium HTCG2181), the recruited reads for $\mathrm{VB}_{12}$ synthesis belonged to different Betaproteobacteria (e.g. Ralstonia solanacearum PSI07 and Chromobacterium violaceum ATCG 12472), which appeared to be much less abundant in this environment (Table S2).

Overall, our transcript data suggests that the vitamin synthesis and utilization potential is compartmentalized among the different members of the microbial community (Figures 1, 2, 3). Some microbial taxa representing a small percent of community transcripts appeared to be nonetheless important synthesizers of some B-vitamins (Figure 2A, Table S3), such as Verrucomicrobia with $\mathrm{VB}_{1}(<4 \%$ of total transcripts but $13 \%$ of $\mathrm{VB}$ synthesis transcripts; dependence:synthesis residual of $-5 \%$ ), Actinobacteria with $\mathrm{VB}_{6}(2 \%$ of total transcripts but $7 \%$ synthesis transcripts; dependence:synthesis residual of $-4 \%$ ), Cyanobacteria with $\mathrm{VB}_{12}(3 \%$ of total transcripts but $9 \%$ of synthesis transcripts; dependence:synthesis residual of $-5 \%$ ) and Methylococcales with $\mathrm{VB}_{12}(1 \%$ of total transcripts but $6 \%$ of synthesis transcripts; dependence:synthesis residual of $-3 \%$ ). Thus, less abundant members of the bacterial assemblage might also be important vitamin producers in the community, and therefore play larger ecological roles than their abundance would suggest. Our data suggest that this coastal marine microbial community is composed of organisms with distinct transcript contributions to vitamin synthesis and utilization. These expression patterns are certainly complex and may be 
bioRxiv preprint doi: https://doi.org/10.1101/280438; this version posted March 14,2018 . The copyright holder for this preprint (which was not certified by peer review) is the author/funder, who has granted bioRxiv a license to display the preprint in perpetuity. It is made available under aCC-BY-NC-ND 4.0 International license.

the result of a combination of diverse regulatory processes that are specific to some taxonomical groups (e.g. eukaryotic phytoplankton; McRose et al., 2014) and are difficult to discern at the community level. Future controlled laboratory studies using specific members of the microbial community will be needed to remove any constraints in our field results.

\section{Seasonal and circadian regulation of B-vitamins gene expression and their potential impact on water-column dissolved vitamin concentrations}

We hypothesized that the ambient dissolved vitamin concentrations measured in the water column should reflect, to some extent, a balance between the synthesis and utilization by the microbial community. During our study, the concentrations of dissolved $\mathrm{VB}_{7}$ and $\mathrm{VB}_{12}$ were the lowest of all, and below our detection limits. These low levels of $\mathrm{VB}_{7}$ and $\mathrm{VB}_{12}$ might suggest a very tight synchronization between synthesis and utilization that may not allow any build-up of these two vitamins in this coastal environment. This hypothetical tight synthesis-uptake coupling, however, was not observed at the level of gene expression, as the dependence:synthesis transcripts for $\mathrm{VB}_{12}$ and $\mathrm{VB}_{7}$ varied over time with no clear temporal patterns (Figure 4). In this study we only quantified the cyanocobalamin form of $\mathrm{VB}_{10}$ and we cannot rule out the presence of the other chemical forms of this vitamin (e.g., pseudo- methyl-, adenosyl- and hydroxo-cobalamin; Suarez-Suarez et al., 2011; Helliwell et al., 2016; Heal et al., 2017; Suffridge et al., 2017). It is unclear how the availability of the different chemical forms of $\mathrm{VB}_{12}$ relate to gene expression and future studies will need to address that issue.

Dissolved $\mathrm{VB}_{1}$ ranged from 0.1 to $5 \mathrm{pM}$ and followed diel oscillations, with consistently higher levels during the day compared to night within each season (Figure 4). However, as for $\mathrm{VB}_{7}$ and $\mathrm{VB}_{12}$, the $\mathrm{VB}_{1}$ dependence:synthesis transcripts did not show any clear diel or seasonal dynamics (Figure 4). We attributed the higher dissolved $\mathrm{VB}_{1}$ concentration during the day to bacterioplankton $\mathrm{VB}_{1}$ production or excretion, as most of the synthesis transcripts belonged to heterotrophic bacteria rather than to small phytoplankton. (Figure 2A, Table S3). Nonetheless, we cannot rule out the impact of the large phytoplankton $(>3 \mu \mathrm{m})$ on vitamin levels as they were not included in our samples. One explanation for the overall higher $\mathrm{VB}_{1}$ concentrations in the day samples could be its function as photo-protectant to oxidative stress during light exposure, as shown for Escherichia coli and Arabidopsis thaliana (Jung and Kim, 2003; Tunc-Ozdemir et al., 2009). Notably, Gifford et al. (2014) showed that the activity of Rhodobacterales (inferred by the expression of ribosomal proteins) in the same metatranscriptomes was also influenced by diel cycles. These similar patterns could indicate a relationship between the activity of Rhodobacterales and the observed higher concentrations of dissolved $\mathrm{VB}_{1}$ found in the day samples, as most Rhodobacterales are auxotrophic for this vitamin or at least for one of its moieties (Table 2). However, the matter of $\mathrm{VB}_{1}$ availability is further complicated by the fact that several microbial groups can

\begin{tabular}{|c|c|c|c|c|c|c|c|c|}
\hline \multirow[b]{2}{*}{ Phylogenetic group } & \multicolumn{8}{|c|}{ Percentage of transcripts invested per taxon } \\
\hline & $\begin{array}{l}\text { VB1 } \\
\text { syn }\end{array}$ & $\begin{array}{l}\text { VB1 } \\
\text { dep }\end{array}$ & $\begin{array}{l}\text { VB6 } \\
\text { syn }\end{array}$ & $\begin{array}{l}\text { VB6 } \\
\text { dep }\end{array}$ & $\begin{array}{l}\text { VB7 } \\
\text { syn }\end{array}$ & $\begin{array}{l}\text { VB7 } \\
\text { dep }\end{array}$ & $\begin{array}{l}\text { VB12 } \\
\text { syn }\end{array}$ & $\begin{array}{l}\text { VB12 } \\
\text { dep }\end{array}$ \\
\hline \multirow{5}{*}{\begin{tabular}{|l|} 
Actinobacteria \\
Rhodobacterales \\
Rhizobiales \\
Rhodospirillales \\
Other unclassified Alphas*
\end{tabular}} & 0.039 & 1.571 & 0.189 & 0.881 & 0.011 & 0.198 & 0.029 & 0.344 \\
\hline & 0.019 & 0.746 & 0.046 & 1.000 & 0.003 & 0.386 & 0.097 & 0.230 \\
\hline & 0.028 & 1.541 & 0.062 & 0.826 & 0.022 & 0.185 & 0.065 & 0.197 \\
\hline & 0.055 & 1.201 & 0.086 & 0.927 & 0.020 & 0.260 & 0.047 & 0.059 \\
\hline & 0.010 & 0.833 & 0.010 & 0.357 & 0.023 & 0.104 & 0.045 & 0.052 \\
\hline \multirow{2}{*}{$\begin{array}{l}\text { SAR11 } \\
\text { SAR116 }\end{array}$} & 0.041 & 0.745 & 0.026 & 0.527 & 0.000 & 0.097 & 0.000 & 0.002 \\
\hline & 0.002 & 0.983 & 0.046 & 0.608 & 0.000 & 0.150 & 0.017 & 0.053 \\
\hline Other alphas & 0.047 & 0.996 & 0.094 & 0.692 & 0.031 & 1.243 & 0.134 & 0.083 \\
\hline Aquificales & 0.059 & 0.429 & 0.112 & 1.268 & 0.018 & 0.270 & 0.012 & 0.023 \\
\hline \multirow{2}{*}{$\begin{array}{l}\text { Bacilli } \\
\text { Flayobacteria }\end{array}$} & 0.063 & 0.595 & 0.074 & 0.783 & 0.008 & 0.241 & 0.025 & 0.127 \\
\hline & 0.023 & 1.085 & 0.009 & 0.063 & 0.122 & 0.430 & 0.009 & 0.003 \\
\hline $\begin{array}{l}\text { Flavobacteria } \\
\text { Sphingobacteria }\end{array}$ & 0.044 & 1.614 & 0.073 & 0.764 & 0.039 & 0.660 & 0.010 & 0.167 \\
\hline Cytophagia & 0.036 & 0.934 & 0.020 & 1.148 & 0.010 & 0.492 & 0.027 & 0.274 \\
\hline Bacteroidia & 0.050 & 0.120 & 0.001 & 0.565 & 0.025 & 0.073 & 0.007 & 0.080 \\
\hline \multirow{2}{*}{$\begin{array}{l}\text { Other bacteroidetes } \\
\text { Betaproteobacteria }\end{array}$} & 0.050 & 0.757 & 0.741 & 7.381 & 0.021 & 0.170 & 0.004 & 1.003 \\
\hline & 0.103 & 1.233 & 0.060 & 0.891 & 0.030 & 0.322 & 0.088 & 0.146 \\
\hline Clostridia & 0.020 & 1.166 & 0.180 & 0.675 & 0.005 & 0.200 & 0.028 & 0.117 \\
\hline \multirow{2}{*}{$\begin{array}{l}\text { Delta-Epsilon proteobacteria } \\
\text { Alteromonadales }\end{array}$} & 0.043 & 0.722 & 0.033 & 0.797 & 0.020 & 0.286 & 0.020 & 0.129 \\
\hline & 0.033 & 0.615 & 0.037 & 0.569 & 0.020 & 0.259 & 0.013 & 0.127 \\
\hline Oceanospirillales & 0.046 & 1.011 & 0.028 & 0.640 & 0.040 & 0.477 & 0.034 & 0.048 \\
\hline Pseudomonadales & 0.099 & 1.471 & 0.071 & 1.092 & 0.022 & 0.235 & 0.017 & 0.071 \\
\hline Unclassified gammas & 0.011 & 0.098 & 0.046 & 0.545 & 0.011 & 0.402 & 0.025 & 0.128 \\
\hline \multirow{2}{*}{ Methylococcales } & 0.085 & 0.779 & 0.069 & 2.620 & 0.120 & 0.386 & 0.097 & 0.255 \\
\hline & 0.216 & 4.532 & 0.020 & 0.377 & 0.009 & 0.099 & 0.218 & 0.204 \\
\hline $\begin{array}{l}\text { Chromatiales } \\
\text { Other gammas }\end{array}$ & 0.047 & 0.659 & 0.072 & 0.813 & 0.027 & 0.279 & 0.016 & 0.090 \\
\hline Planctomycetes & 0.040 & 0.419 & 0.056 & 0.399 & 0.010 & 0.210 & 0.050 & 0.196 \\
\hline Verrucomicrobia & 0.163 & 1.011 & 0.032 & 0.749 & 0.033 & 0.505 & 0.015 & 0.225 \\
\hline \multirow{2}{*}{$\begin{array}{l}\text { Cyanobacteria } \\
\text { Deinococci }\end{array}$} & 0.077 & 0.572 & 0.095 & 0.759 & 0.027 & 0.241 & 0.147 & 0.101 \\
\hline & 0.007 & 0.756 & 0.266 & 0.795 & 0.004 & 0.156 & 0.596 & 0.475 \\
\hline $\begin{array}{l}\text { Deinococci } \\
\text { Archaea }\end{array}$ & 0.035 & 0.162 & 0.080 & 0.280 & 0.006 & 0.040 & 0.038 & 0.283 \\
\hline Eukaryotes & 0.005 & 0.080 & 0.005 & 0.095 & 0.001 & 0.094 & 0.002 & 0.027 \\
\hline \multirow{2}{*}{$\begin{array}{l}\text { Viruses } \\
\text { Other bacteria }\end{array}$} & 0.000 & 0.034 & 0.000 & 0.021 & 0.000 & 0.000 & 0.057 & 0.000 \\
\hline & 0.021 & 0.829 & 0.102 & 1.081 & 0.012 & 0.291 & 0.050 & 0.540 \\
\hline Average community & 0.038 & 0.780 & 0.053 & 0.687 & 0.020 & 0.279 & 0.043 & 0.135 \\
\hline
\end{tabular}

Figure 3. Percentage of transcripts invested in B-vitamin metabolism (B-vitamin synthesis or dependence) for each phylogenetic group. Heatmap colors designate the level of transcriptome investment compared to the average microbial community. White background represents the average percent investment, while green are above and orange are below average, respectively. $* U n-$ classified alphaproteobacteria outside the SAR11 group.

only meet their biological demands with the uptake of $\mathrm{VB}_{1}$ precursors instead of the complete $\mathrm{VB}_{1}$ molecule (Carini et al., 2014). Even though we did not quantify the different moieties of this vitamin, knowing the standing stock of $\mathrm{VB}_{1}$ is relevant, as some of its decomposition products could be used for cellular growth by diverse phytoplankton groups (Gutowska et al., 2017). Future studies will need to address the effect of $\mathrm{VB}_{1}$ moieties and pathway intermediates in natural communities as recently established in culture growth studies (Gutowska et al., 2017; Paerl et al., 2017).

The levels of dissolved $\mathrm{VB}_{6}$ ranged from 0.1 to $8.9 \mathrm{pM}$ and were also higher in the day samples, except for winter '09 when all $\mathrm{VB}_{6}$ concentrations were below our detection limit $\left(<0.1 \mathrm{pM}\right.$; Figure 4). Similar to $\mathrm{VB}_{1}$, the higher $\mathrm{VB}_{6}$ concentrations during the day could be explained by its function as antioxidant during light exposure (Bilski et al., 2000; Mooney et al., 2009). In fact, the antioxidant properties of $\mathrm{VB}_{6}$ against oxidative stress even exceed those of vitamins $\mathrm{C}$ and $\mathrm{E}$ (Ehrenshaft et al., 1999). Furthermore, this coenzyme is particularly important in amino acid metabolism (e.g. amino acid synthesis and transaminations; Hayashi, 1995), which may be more relevant during the night (Cuhel et al., 1984; Poretsky et al., 2009; Gifford et 
bioRxiv preprint doi: https://doi.org/10.1101/280438; this version posted March 14,2018 . The copyright holder for this preprint (which was not certified by peer review) is the author/funder, who has granted bioRxiv a license to display the preprint in perpetuity. It is made available under aCC-BY-NC-ND 4.0 International license.

al., 2014). Yet, we did not observe diel oscillations in $\mathrm{VB}_{6}$ dependence:synthesis transcript ratios. . This is in contrast to a metatranscriptomic study in the South Pacific, in which the expression of $\mathrm{VB}_{6}$ synthesis genes was higher during the night compared to the day (Poretsky et al., 2009). Additional studies analyzing intracellular B-vitamin concentrations will be necessary to identify their circadian fluctuations in relation to the internal cellular processes over time.

The observed higher dissolved B-vitamin concentrations during sunlight exposure could have important consequences for the functioning of the marine microbial community. An obvious one is that vitamin auxotrophs that take advantage of this source would end up following the same circadian rhythm as the vitamin producers. Ottesen et al. (2014) reported a tight diel synchronization between the metatranscriptomes of the cyanobacteria
Prochlorococcus and heterotrophic bacterioplankton in situ, suggesting an interaction (direct or indirect) between these organisms (Ottesen et al., 2014; Armbrust, 2014). In our study, dissolved $\mathrm{VB}_{1}$ concentrations were positively correlated to Chl-a throughout the yearlong dataset (Figure 5). Although a direct cause-effect relationship between the two parameters has not been demonstrated, this vitamin is involved in carbon fixation during the Calvin cycle (SañudoWilhelmy et al., 2014; Monteverde et al., 2017). Because the $\mathrm{VB}_{1}$ dependent transcripts of eukaryotic picophytoplankton were low, the correlation between dissolved $\mathrm{VB}_{1}$ and total Chl-a may involve the larger phytoplankton community not sampled by our size-fractionation scheme $(0.2>3 \mu \mathrm{m})$. Further studies will be needed to evaluate the cause of the observed $\mathrm{VB}_{1} / \mathrm{Chl}-a$ relationship and confirm the identity of the key organisms responsible for this interdependence. In contrast to the strong correlation between $\mathrm{VB}_{1}$ and Chl-a,
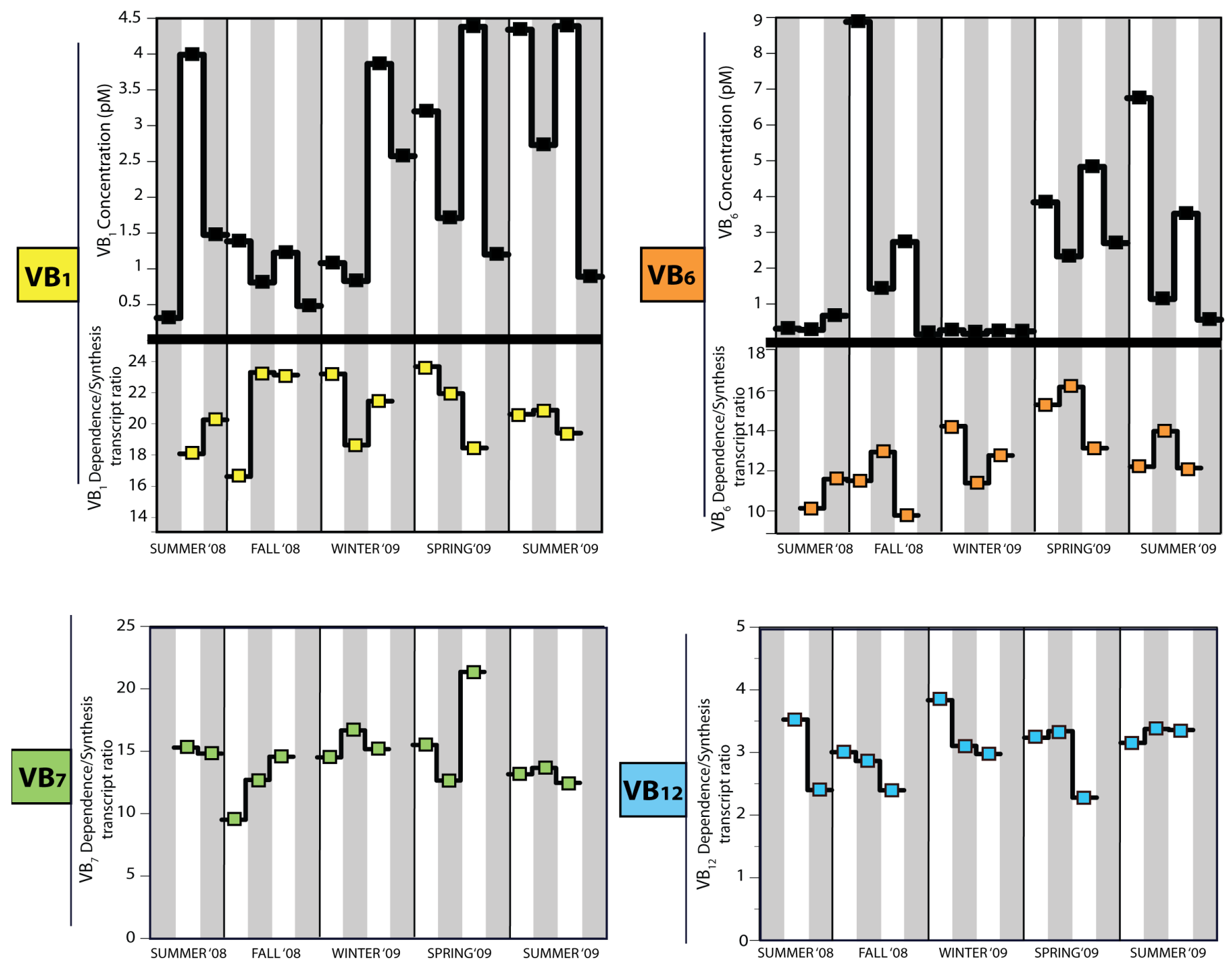

Figure 4. Environmental concentrations of dissolved $\mathrm{VB}_{1}$ and $\mathrm{VB}_{6}$ compared to the vitamin dependence:synthesis transcript ratios. Concentrations of dissolved $\mathrm{VB}_{7}$ and $\mathrm{VB}_{12}$ were below our detection limit and only the vitamin dependence:synthesis transcript ratios are shown. Grey and white background denotes night and day samples, respectively. Specific concentrations and times of sampling are shown in Table S6. 
we did not find any relationship between the concentrations of dissolved $\mathrm{VB}_{6}$ and phytoplankton biomass (Figure 5).

Although the auxotrophy for $\mathrm{VB}_{1}, \mathrm{VB}_{7}$ and $\mathrm{VB}_{12}$ has been recognized in marine microbes for decades (Provasoli, 1963; Provasoli and Carlucci, 1974; Croft et al., 2005; Sañudo-Wilhelmy et al., 2014), $\mathrm{VB}_{6}$ dependence had not yet been considered. Indeed, $\mathrm{VB}_{6}$ auxotrophy is likely to be minor as the $\mathrm{VB}_{6}$ synthesis pathway is widespread in free-living microorganisms and plants and more than a hundred enzymatic reactions are catalyzed by this coenzyme (Hayashi, 1995). Nonetheless, our results suggest that some members of the microbial community express more $\mathrm{VB}_{6}$ synthesis transcripts than others in relation to their total transcript contribution to the community and their vitamin requirement transcripts (Figure 2). Moreover, if the excess of $\mathrm{VB}_{6}$ is released to the environment on daily basis, it is possible that at least some taxa have adapted to take advantage of this source to reduce their vitamin synthesis requirements. Finally, because the inferred vitamin metabolism in this coastal community involves bacterial groups that are cosmopolitan, our findings could potentially be extrapolated to other marine environments.

\section{Experimental procedures}

\section{Sample collection}

Samples for metatranscriptomics were collected quarterly (2008: August 6-7, November 5-7; 2009: February 15-17, May 13-15, August 12-14) at Marsh Landing, Sapelo Island, Georgia, U.S.A. $\left(31^{\circ} 25^{\prime} 4.08 \mathrm{~N}, 81^{\circ} 17^{\prime} 43.26 \mathrm{~W}\right)$ as part of the Sapelo Island Microbial Observatory program (http:// simco.uga.edu). Sampling occurred at four consecutive high tides resulting in two consecutive pairs of day-night samples per season. Additional samples were collected for specific environmental measurements including chlorophyll-a and dissolved B-vitamins. RNA from the water samples was extracted as previously described (Poretsky et al., 2009; Gifford et al., 2011; 2013; 2014). Briefly, 6-8 L were directly

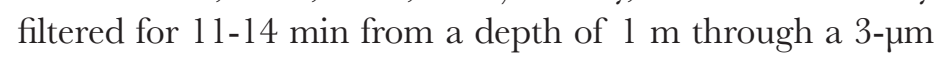
pore-size prefilter to exclude larger microbial fractions (Capsule Pleated Versapor Membrane; Pall Life Sciences, Ann Arbor, MI, USA) and 0.22- $\mu \mathrm{m}$ pore-size filter (Supor polyethersulfone; Pall Life Sciences). The 0.22- $\mu \mathrm{m}$ filter was immediately flash frozen in liquid nitrogen until RNA processing and sequencing.

\section{RNA processing and sequencing}

Samples were processed as earlier described (Gifford et al., 2011; 2013; 2014). Total RNA was extracted using a RNAEasy kit (Qiagen) and DNA was removed using a Turbo DNA-free kit (Applied Biosystems, Austin, TX, USA). mRNA was enriched via enzymatic rRNA reduction using Epicentre's mRNAOnly isolation kit (Madison,

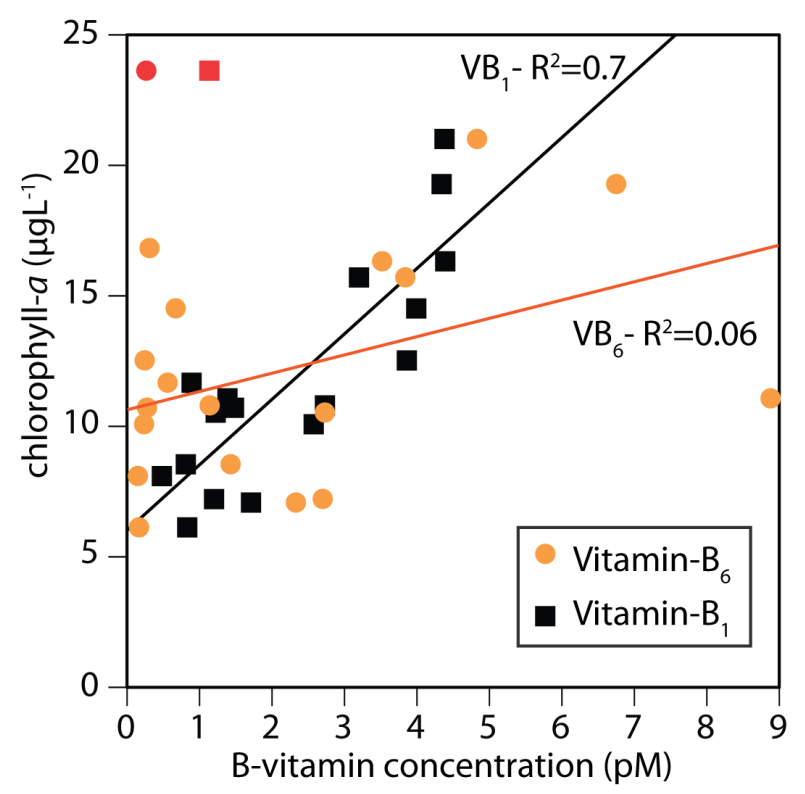

Figure 5. Correlation between total chlorophyll-a and dissolved $\mathrm{VB}_{1}$ and $\mathrm{VB}_{6}$ concentrations. The red data points are considered outliers and were excluded from the statistical analysis; those correspond to the sample collected in winter ' 09 .

WI, USA) and subsequently with MICROBExpress and MICROBEnrich rRNA (Applied Biosystems) subtractive kits. Enriched mRNA samples were linearly amplified using the MessageAmp II-Bacteria kit (Applied Biosystems) and double stranded cDNA synthesized with Promega's Universal RioboClone cDNA synthesis system and random primers. cDNA synthesis reactions were cleaned up with a QIAquick PCR purification kit (Qiagen). Samples were sheared and size-selected to $\sim 300 \mathrm{bp}$ and sequenced with an Illumina GAIIX to obtain $150 \times 150$ bp paired end reads.

\section{Bioinformatics pipeline}

Reads with an average quality score $\leq 20$ and a length $<100$ bp were removed and overlapping paired end reads from each fragment were assembled using SHERA (Rodrigue et al., 2010) with a score $>0.5$ (Gifford et al., 2013; 2014). Sequences were combined from all samples, subsampled to 25,000 reads, and searched against the SILVA small and large subunit databases using BLASTn (Altschul et al., 1998) with bit score $\geq 50$ to create a more compact database for further rRNA gene filtering. The total reads from all metatranscriptomes were then filtered using BLASTn against the compact database. Putative non-rRNA sequences were then searched against the National Center for Biotechnology Information's (NCBI; http://www.ncbi.nlm.nih.gov) RefSeq protein database (version 43, September 2010) using BLASTx with a bit score cutoff $\geq 50$ to identify protein encoding sequences. Functional annotation and taxonomy 
were assigned based on the top scoring hit to RefSeq. RefSeq counts for each sample were randomly subsampled (van Rossum, 2010; McKinney, 2010) to the total number of non-rRNA reads of the smallest library (1,332,199 reads) to account for variation in sample sequencing effort.

\section{Annotation of vitamin related transcripts}

Vitamin related transcripts for $\mathrm{VB}_{1}$ (thiamin monophosphate; TMP or thiamin pyrophosphate; TPP), $\mathrm{VB}_{6}$ (pyridoxal 5'-phosphate), $\mathrm{VB}_{7}$ and $\mathrm{VB}_{12}$ (methylcobalamin, adenosylcobalamin, hydroxocobalamin) were identified by text-based query for either the EC number, gene or enzyme name in the retrieved RefSeq functional annotations. The specific vitamin synthesis genes and vitamin dependent enzymes are listed in Table S1 and all vitamin-related hits are included in supplementary Table S2. For each of the vitamins $\left(\mathrm{VB}_{1}, \mathrm{VB}_{6}, \mathrm{VB}_{7}, \mathrm{VB}_{12}\right)$, vitamin dependent enzymes were identified using the ExPASy database (http://www. expasy.org) and are defined as the metabolic reactions that require a specific B-vitamin as co-enzyme. Vitamin synthesis functional annotations are those enzymes that belong to the synthesis pathway of a specific B-vitamin, and were determined using the Kyoto Encyclopedia of Genes and Genomes (KEGG; http://www.genome.jp/kegg/)(Table $\mathrm{S} 2$ ). For $\mathrm{VB}_{7}$ synthesis pathway, the genes fabI, fabB, fabG and fabZ were not included in our analysis, as they are also part of the fatty acid biosynthesis pathways and are present in most microorganisms including vitamin- $B_{7}$ auxotrophs. Therefore including those genes would produce false positives. Sequences were also classified by sequence similarity to a list of vitamin synthesis/dependence genes in order to verify that RefSeq description annotation precisely represents counts of vitamin synthesis and dependence. Sequences for synthesis and dependence of each vitamin were retrieved from the RefSeq protein database. All sequences were searched against separate BLAST databases for synthesis and dependence of each vitamin (e. g. $\mathrm{VB}_{6}$ dependence and $\mathrm{VB}_{6}$ synthesis). Only matches with a bit score $\geq 40$ and that do not have a higher scoring non-vitamin RefSeq match were retained. This strategy produced slightly underestimated counts of vitamin synthesis/dependence classifications (86 $\pm 4.2 \%$; Table S5), but did not affect the overall pattern of vitamin usage.

\section{Identification of taxa involved in B-vitamin synthesis and utilization}

Linear modeling robust to outliers was employed to identify taxa that disproportionately contributed to vitamin synthesis or dependence gene expression above the typical expression for the whole community. Iterated re-weighted least squares (IWLS) linear regression was fit with $1 \mathrm{x}$ 106 maximum iterations for outlier removal between synthesis:total expression, dependence:total expression, and dependence:synthesis using the "MASS" R-package (Venables and Ripley, 2013). Ratios near the linear regression line (low residuals) are defined as typical for the microbial community. A positive residual suggests a ratio greater than the typical ratio, whereas a negative residual is less than the typical ratio. For example, the negative Cyanobacteria dependence:synthesis residual for $\mathrm{VB}_{1}$ suggests that Cyanobacteria are important synthesizers of $\mathrm{VB}_{1}$. Underlying this analytical approach is the assumption that vitamin requirements scale similarly with vitamin-dependent transcripts for all taxonomic groups (i.e., a vitamin dependent transcript represents an equivalent vitamin requirement across all taxa). The synthesis:dependence regression lines of each vitamin could be influenced by the fact that particular taxa are auxotrophs for a particular vitamin (e.g. eukaryotes and $\left.\mathrm{VB}_{12}\right)$, and by different taxa having varied numbers of enzymes that require the vitamin. For instance, there are more than 20 enzymes that require $\mathrm{VB}_{12}$ in prokaryotes (Marsh 1999), and only three $\mathrm{VB}_{12}$ dependent enzymes in eukaryotes (Helliwell et al., 2011). Another example is $\mathrm{VB}_{1}$ which, among other functions, is used by enzymes in the Calvin cycle of photoautotrophs and this cycle will be absent in heterotrophic microorganisms. Finally, as in any other metatranscriptomic analysis, our results could not account for any post-transcriptional regulation.

\section{Chlorophyll-a quantification}

Chlorophyll a analysis was done as described in Parsons et al. (1984). Seawater samples of $250 \mathrm{ml}$ were filtered onto GFF membranes (Whatman plc, Maidstone, United Kingdom), placed in conical tubes filled with $50 \mathrm{ml}$ of $90 \%$ acetone, and stored at $-20^{\circ} \mathrm{C}$ until analysis. Sample fluorescence was measured by sonicating the samples for 30 seconds, then adding $3 \mathrm{ml}$ to a $5 \mathrm{~cm}$ quartz cuvette, and measuring on a Turner fluorometer. Estimates of phaoe-pigments were obtained by acidifying the same sample with $10 \% \mathrm{HCl}$ and rerunning on the fluorometer. Sample chlorophyll-a concentrations were then calculated based on comparison to a standard curve of fluorescence from chlorophyll-a standards.

\section{Quantification of dissolved B-vitamins in situ}

The concentration of dissolved B-vitamins was determined using HPLC-MS after pre-concentration of $500 \mathrm{~mL}$ of 0.2 $\mu \mathrm{m}$-filtered seawater. Dissolved samples were preconcentrated by passing the sample over a $\mathrm{C} 18$ resin at two $\mathrm{pHs}$ (6.5 and 2.0), followed by elution with $12 \mathrm{ml}$ of methanol. A nitrogen $\left(\mathrm{N}_{2}\right)$ dryer was used to evaporate the samples to about 250 $\mu \mathrm{l}$. Quantification of dissolved B-vitamins, $\mathrm{VB}_{1}$ as thiamin hydrochloride $\left(\mathrm{C}_{12} \mathrm{H}_{17} \mathrm{ClN}_{4} \mathrm{OS} * \mathrm{HCl}\right), \mathrm{VB}_{6}$ as pyridoxine 
hydrochloride $\left(\mathrm{C}_{8} \mathrm{H}_{11} \mathrm{NO}_{3} * \mathrm{HCl}\right), \mathrm{VB}_{7}$ as biotin $\left(\mathrm{C}_{10} \mathrm{H}_{16} \mathrm{~N}_{2} \mathrm{O}_{3} \mathrm{~S}\right)$ and $\mathrm{VB}_{12}$ as cyanocobalamin $\left(\mathrm{C}_{63} \mathrm{H}_{88} \mathrm{CoN}_{14} \mathrm{O}_{14} \mathrm{P}\right)$, was conducted using a Thermo Scientific Quantum Access electrospray ionization triple quadrupole mass spectrometer, coupled to a Thermo Scientific Accela High Speed Liquid Chromatography (LC/MS) system. The LG system used a stable-bond C18 reversed-phase column (Discovery HS C18 $10 \mathrm{~cm} \times 2.1 \mathrm{~mm}, 5 \mu \mathrm{m}$ column, Supelco Analytical), with a methanol:water gradient program. A full description of the analytical protocol for the vitamins quantification including all of the MS operating conditions have been reported elsewhere (Sañudo-Wilhelmy et al., 2012). Although our analytical protocol is able to measure a suite of B-vitamins, the small volume of the water samples did only allow the determination of vitamins found at relatively high concentrations such as thiamin and pyridoxine (both measured against standards prepared in their hydrochloride forms). The concentrations of dissolved $\mathrm{VB}_{7}$ and $\mathrm{VB}_{12}$ were below our detection limit in all samples $(<0.1 \mathrm{pM})$.

Acknowledgments. This project was founded by the Marie Curie Actions-International Outgoing Fellowships (project 253970) and the US National Science Foundation grant OCE-1435666.

Author contributions. LG-C and MM designed the study. SG collected and processed field samples. LG and SS-W analyzed B-vitamin concentrations. LG-C, RS, SG, LC, JF, SS-W, MM analyzed data and contributed to the writing of the paper.

Author information. The authors declare no conflict of interest. Correspondence and request for materials should be addressed to LG-G (gomezcon@usc.edu).

\section{References}

Altschul S,. Madden, T., Schaffer, A. (1998) Gapped BLAST and PSIBLAST: A new generation of protein database search programs. Nucleic Acids Res 25:3389-3402

Armbrust, E.V. (2014). Taking the pulse of ocean microbes. Science 345: 134-135.

Azam, F., Fenchel, T., Field, J.G., Gray, J.S., Meyerreil, L.A., Thingstad, F. (1983). The Ecological Role of Water-Column Microbes in the Sea. Mar Ecol Prog Ser 10: 257-263.

Bertrand, E.M., McCrow, J.P., Moustafa, A., Zheng, H., McQuaid, J.B., Delmont, T.O., Post, A.F., Sipler, R.E., Spackeen, J.L., Xu, K., Bronk, D.A., Hutchins, D.A., Allen, A.E. (2015). Phytoplankton-bacterial interactions mediate micronutrient colimitation at the coastal Antarctic sea ice edge. Proc Natl Acad Sci USA 1 12:9938-9943.

Bilski, P., Li, M.Y., Ehrenshaft, M., Daub, M.E., Chignell, C.F. (2000). Vitamin B6 (pyridoxine) and its derivatives are efficient singlet oxygen quenchers and potential fungal antioxidants. Photochem Photobiol 71: 129-134.

Bonnet, S., Webb, E.A., Panzeca, C., Karl, D.M., Capone, D.G., Sañudo-Wilhelmy, S.A. (2010). Vitamin B12 excretion by cultures of the marine cyanobacteria Crocosphaera and Synechococcus. Limnol. Oceanogr 55:1959-64

Carini, P., Campbell, E.O., Morré, J., Sañudo-Wilhelmy, S.A., Thrash, J.C., Bennett, S.E., et al. (2014). Discovery of a SAR11 growth requirement for thiamin's pyrimidine precursor and its distribution in the Sargasso Sea. ISME J 8: 1727-1738.

Carini, P., Steindler, L., Beszteri, S., Giovannoni, S.J. (2012). Nutrient requirements for growth of the extreme oligotroph Candidatus Pelagibacter ubique HTCG1062 on a defined medium. ISME J 7: 592-602.

Cohen, N.R., Ellis, K.A., Burns, W.G., Lampe, R.H., Schuback, N., Johnson, Z., Sañudo-Wilhelmy, S.A., Marchetti, A. (2017) Iron and vitamin interactions in marine diatoms of the Northeast Pacific Ocean. Limnol Oceanogr. 62:2076-2096.

Croft, M.T., Lawrence, A.D., Raux-Deery, E., Warren, M.J., Smith, A.G. (2005). Algae acquire vitamin B12 through a symbiotic relationship with bacteria. Nature 438: 90-93.

Croft, M., Warren, M.J., Smith, A.G. (2006). Algae need their vitamins. Eukaryot. Cell 5:1175-83.

Guhel, R.L., Ortner, P.B., Lean, D. (1984). Night synthesis of protein by algae. Limnol Oceanogr. Limnol Oceanogr 29:731744.

Ehrenshaft, M., Bilski, P., Li, M.Y., Chignell, C.F., Daub, M.E. (1999). A highly conserved sequence is a novel gene involved in de novo vitamin B6 biosynthesis. Proc Natl Acad Sci USA 96: 9374-9378.

Gifford, S.M., Sharma, S., Booth, M., Moran, M.A. (2013). Expression patterns reveal niche diversification in a marine microbial assemblage. ISME J 7: 281-298.

Gifford, S.M., Sharma, S., Moran, M.A. (2014). Linking activity and function to ecosystem dynamics in a coastal bacterioplankton community. Front Microbiol 5:185.

Gifford, S.M., Sharma, S., Rinta-Kanto, J.M., Moran, M.A. (2011). Quantitative analysis of a deeply sequenced marine microbial metatranscriptome. ISME J 5: 461-472.

Giovannoni, S.J., Tripp, H.J., Givan, S., Podar, M., Vergin, K.L., Baptista, D., et al. (2005). Genome streamlining in a cosmopolitan oceanic bacterium. Science 309: 1242-1245.

Gómez-Consarnau L., González, J.M., Riedel, T., Jaenicke, S., Wagner-Döbler, I., Sañudo-Wilhelmy, S.A. and Fuhrman, J.A. (2016). Proteorhodopsin light-enhanced growth linked to vitamin-B1 acquisition in marine Flavobacteria. ISME J 10: 1102-1112.

Gutowska, M.A., Shome, B., Sudek, S., McRose, D.L., Hamilton, M., Giovannoni, S.J., Begley, T.P., Worden, A.Z. (2018). Globally important haptophyte algae use exogenous pyrimidine compounds more efficiently than thiamin. mBio 8:e01459-17.

Hayashi, H. (1995). Pyridoxal Enzymes - Mechanistic Diversity and Uniformity. J Biochem 118: 463-473. 
Heal, K. R., Qin, W., Ribalet, F., Bertagnolli, A. D., Coyote-Maestas, W., Hmelo, L. R., et al. (2017). Two distinct pools of B12 analogs reveal community interdependencies in the ocean. Proc Natl Acad Sci USA 114; 364-369.

Helliwell, K.E., Wheeler, G.L., Leptos, K.G., Goldstein, R.E., Smith, A.G. (2011). Insights into the evolution of vitamin B-12 auxotrophy from sequenced algal genomes. Mol Biol Evol 28: 2921-2933.

Helliwell KE, Lawrence AD, Holzer A, Kudahl UJ, Sasso S, Kräutler B, Scanlan DJ, Warren MJ, Smith AG. (2016). Cyanobacteria and Eukaryotic Algae Use Different Chemical Variants of Vitamin B12. Curr Biol 26:999-1008.

Hollibaugh, J.T., Gifford, S., Sharma, S., Bano, N., Moran, M.A. (2011). Metatranscriptomic analysis of ammonia-oxidizing organisms in an estuarine bacterioplankton assemblage. ISME J 5: 866-878.

Hollibaugh, J.T., Gifford, S.M., Moran, M.A., Ross, M.J., Sharma, S., Tolar, B.B. (2013). Seasonal variation in the metratranscriptomes of a Thaumarchaeota population from SE USA coastal waters. ISME J 8: 685-698.

Hutchinson, G.E. The paradox of the plankton. The American Naturalist 95: 137-145.

Jung, I.L., Kim, I.G. (2003). Thiamine protects against paraquatinduced damage: scavenging activity of reactive oxygen species. Environ Toxicol Pharmacol 15: 19-26.

Kazamia, E., Czesnick, H., Nguyen, T.T.V., Croft, M.T., Sherwood, E., Sasso, S., et al. (2012). Mutualistic interactions between vitamin B12 -dependent algae and heterotrophic bacteria exhibit regulation. Environ Microbiol 14: 1466-1476.

Kirchman, D.L. (2002). The ecology of Cytophaga-Flavobacteria in aquatic environments. FEMS Microbiol Ecol 39: 91-100.

Koch, F., Marcoval, M. A., Panzeca, C., Bruland, K. W., SañudoWilhelmy, S. A., and Gobler, C. J. (2011). The effect of vitamin $\mathrm{B}(12)$ on phytoplankton growth and community structure in the Gulf of Alaska. Limnol. Oceanogr. 56: 1023-1034.

Kurata, A. (1986). Chrysophytes: Aspects and Problems, J.A. Kristiansen, ed. (Cambridge University Press), pp. 185-196.

LeBlanc, J.G., Laino, J.E., del Vall, M.J., Vannini, V., van Sinderen, D., Taranto, M.P., etal. (2011) B-group vitamin production by lactic acid bacteria - current knowledge and potential applications. J Appl Microbiol 111: 1297-1309.

Marsh, E.N. (1999). Coenzyme B12 (cobalamin)-dependent enzymes. Essays Biochem. 34:139-154

McGarren, J., Becker, J.W., Repeta, D.J. (2010). Microbial community transcriptomes reveal microbes and metabolic pathways associated with dissolved organic matter turnover in the sea. Proc Natl Acad Sci USA 107:16420-16427.

McKinney, W. (2010). Data structures for statistical computing in python. in Proceedings of the 9th Python in Science Conference, pp. 51-56.

McRose, D., Guo, J., Monier, A., Sudek, S., Wilken, S., Yan, S., Mock, T., Archibald, J. M., Begley, T. P., Reyes-Prieto, A., \& Worden, A. Z. (2014). Alternatives to vitamin Bl uptake revealed with discovery of riboswitches in multiple marine eukaryotic lineages. ISME J. 8:2517-2529.

Monteverde, D.M., Gómez-Consarnau, L., Suffridge, G., SañudoWilhelmy, S.A. (2017). Life's utilization of B Vitamins on early Earth. Geobiology 15:3-18.

Mooney, S., Leuendorf, J-E., Hendrickson, C., Hellmann, H. (2009). Vitamin B6: A Long Known Compound of Surprising Complexity. Molecules 14: 329-351.

Moran, M.A. (2008). Genomics and metagenomics of marine prokaryotes. Microbial Ecology of the Oceans. 2nd edn.Wiley-Liss: New York

Ottesen, E.A., Young, G.R., Gifford, S.M., Eppley, J.M., Marin, R. (2014). Multispecies diel transcriptional oscillations in open ocean heterotrophic bacterial assemblages. Science 34:207-212.

Paerl, R.W., Bertrand, E.M., Allen, A.E., Palenik, B., Azam, F. (2015). Vitamin B1 ecophysiology of marine picoeukaryotic algae: Strainspecific differences and a new role for bacteria in vitamin cycling. Limnol Oceanogr 60:215-228.
Paerl, R.W., Bouget, F.-Y., Lozano, J.-C., Vergé, V., Schatt, P., Allen, A. E., Palenik, B., Azam, F. (2017). Use of plankton-derived vitamin $\mathrm{B} 1$ precursors, especially thiazole-related precursor, by key marine picoeukaryotic phytoplankton. ISME J 11:753-765.

Panzeca, C., Tovar-Sanchez, A., Agustí, S., Reche, I., Duarte, C. M., Taylor, G. T., et al. (2006). B vitamins as regulators of phytoplankton dynamics. Eos Trans Am Geophys Union 87: 593-596.

Parsons, T.R., Maita, Y., Lalli, C.M. (1984). Determination of chlorophylls and total carotenoids: spectrophotometric method. Parsons, TR, Y. Maita and CM Lalli. A manual of chemical and biological methods for seawater analysis. Pergamon Press, Oxford. 101-12.

Pedrós-Alió, C. (2012). The Rare Bacterial Biosphere. Annu Rev Marine Sci 4: 449-466.

Percudani, R., Peracchi, A. (2003). A genomic overview of pyridoxalphosphate-dependent enzymes. EMBO Rep 4:850-854.

Poretsky, R.S., Hewson, I., Sun, S., Allen, A.E., Zehr, J.P., Moran, M.A. (2009). Comparative day/night metatranscriptomic analysis of microbial communities in the North Pacific subtropical gyre. Environ Microbiol 11: 1358-1375.

Provasoli L. (1963). Organic regulation of phytoplankton fertility. In The Sea, Vol. 2, Composition of Sea-Water. Comparative and Descriptive Oceanography, ed. MH Hill, pp. 165-219. New York: Interscience.

Provasoli L, Carlucci AF. (1974). Vitamins and growth regulators. In Algal Physiology and Biochemistry, ed.WDP Steward, pp. 741-87. Berkeley: Univ. Calif. Pres.

Raes, J., Bork, P. (2008). Molecular eco-systems biology: towards an understanding of community function. Nat Rev Micro 6: 693-699.

Rodrigue, S., Materna, A.C., Timberlake, S.C., Blackburn, M.C., Malmstrom, R.R., Alm, E.J., et al. (2010). Unlocking Short Read Sequencing for Metagenomics Gilbert JA (ed). PLoS ONE 5: el1840.

Sañudo-Wilhelmy, S.A., Cutter, L.S., Durazo, R., Smai,l E.A., GomezConsarnau, L., Webb, E.A., et al. (2012). Multiple B-vitamin depletion in large areas of the coastal ocean. Proc Natl Acad Sci USA 109:14041-14045.

Sañudo-Wilhelmy, S.A., Gobler, C.J., Okbamichael, M., Taylor, G.T. (2006). Regulation of phytoplankton dynamics by vitamin B 12. Geophys Res Lett 33: L04604.

Sañudo-Wilhelmy, S.A., Gomez-Consarnau, L., Suffridge, C., Webb, E.A. (2014). The role of B vitamins in marine biogeochemistry. Annu Rev Marine Sci 6: 339-367.

Sogin, M.L., Morrison, H.G., Huber, J.A., Mark Welch, D., Huse, S.M., Neal, P.R., et al. (2006). Microbial diversity in the deep sea and the underexplored "rare biosphere". Proc Natl Acad Sci USA 103: 12115-12120.

Suárez-Suárez, A., Tovar-Sánchez, A., and Rosselló-Mora, R. (2011). Determination of cobalamins (hydroxo-, cyano-, adenosyland methyl-cobalamins) in seawater using reversed-phase liquid chromatography with diode-array detection. Anal Chim Acta 701: 81-85.

Suffridge, G., Cutter, L.S., Sañudo-Wilhelmy, S.A. (2017). A new analytical method for direct measurement of particulate and dissolved B-vitamins and theircongeners in seawater. Front Mar Sci $4: 1-11$.

Tang, Y.Z., Koch, F., Gobler, C.J. (2010). Most harmful algal bloom species are vitamin B1 and B12 auxotrophs. Proc Natl Acad Sci USA 107: 20756-20761.

Taniguchi, Y., Choi, P.J., Li, G-W, Chen, H., Babu, M., Hearn, J., et al. (2010). Quantifying E. coli proteome and transcriptome with singlemolecule sensitivity in single cells. Science 329:533-538.

Teeling, H., Fuchs, B.M., Becher, D., Klockow, C., Gardebrecht, A., Bennke, C.M., et al. (2012). Substrate-Controlled Succession of Marine Bacterioplankton Populations Induced by a Phytoplankton Bloom. Science 336: 608-611.

Tunc-Ozdemir, M., Miller, G., Song, L., Kim, J., Sodek, A., Koussevitzky, S., et al. (2009). Thiamin Confers Enhanced Tolerance to Oxidative Stress in Arabidopsis. Plant Physiology 151: 421-432.

Van Rossum, G. et al. (2010) The Python programming language. Python Softw URL http:/ / python. org 
bioRxiv preprint doi: https://doi.org/10.1101/280438; this version posted March 14,2018. The copyright holder for this preprint (which was not certified by peer review) is the author/funder, who has granted bioRxiv a license to display the preprint in perpetuity. It is made available under aCC-BY-NC-ND 4.0 International license.

Venables, W.N., Ripley, B.D- (2013) Modern applied statistics with S-PLUS.

Wagner-Döbler, I., Ballhausen, B., Berger, M., Brinkhoff, T., Buchholz, I., Bunk, B., et al. (2010). The complete genome sequence of the algal symbiont Dinoroseobacter shibae: a hitchhiker's guide to life in the sea. ISME J 4: 61-77.

\section{Supporting Information}

Additional Supporting Information may be found in the online version of this article:

Table S1. List of B-vitamin synthesis and B-vitamin dependent functions used in the metatranscriptome analysis. Vitamin dependent functions were identified using the ExPASy database (http://www.expasy.org) and vitamin synthesis genes were identified using the Kyoto Encyclopedia of Genes and Genomes (KEGG; http://www.genome.jp/ $\mathrm{kegg} /$ ). In addition to the listed enzymes, the reads annotated as "vitamin synthesis" or "vitamin dependent/requiring" included in Table S2 and Table S3 were also included.

Table S2. List of all B-vitamin synthesis and B-vitamin dependentfunction readsidentifiedinthemetatranscriptomics dataset. In addition to the enzymes listed in table S1, reads annotated as "vitamin synthesis" or "vitamin dependent/ requiring" were also included.

Table S3. Summary of the B-vitamin synthesis and dependent gene transcript abundance for the bestrepresented taxonomic groups in each individual sample.

Table S4. Percentages of B-vitamin synthesis and dependence transcripts in different microbial taxa and regression lines shown in Figure 2.

Table S5. Comparison of annotation methods for vitamin synthesis and dependence transcripts. To verify that RefSeq description annotation accurately represents counts of vitamin synthesis and dependence, reads were also classified by sequence similarity to a list of vitamin synthesis and dependence genes. Reference sequences for synthesis and dependence genes of each vitamin were retrieved from the RefSeq protein database. Metagenomic reads were searched against separate BLAST databases for the synthesis and dependence genes associated with each vitamin. Only matches with a bit score $>=40$ and that did not have a higher scoring non-vitamin RefSeq match were retained.

Table S6. Environmental concentrations of Chlorophyll-a, vitamin $B_{1}$ and $B_{6}$ and specific sampling times. 